\title{
Micronutrients in childhood nutrition
}

Pujitha Wickramasinghe ${ }^{1}$

Sri Lanka Journal of Child Health, 2013; 42(4): 157-165

(Key words: micronutrients; child; nutrition)

Growth is the key biological factor that distinguishes the paediatric population from adults. Early childhood growth has a great impact on the future health of an individual. In that context, proper nutrition in early life is important to harness the maximum growth and functional potential of an individual and to prevent non-communicable diseases (NCDs) later on in life. Undernutrition occurs not only due to macronutrient deficiencies but also due to micronutrient deficiencies. The latter are less obvious, thus earning the name "hidden hunger". Patients and clinicians tend to recognize the existence of a deficiency only once they encounter a clinical condition or a problem. However, subclinical forms of nutritional deficiencies are forgotten entities but these could last for a long period of time and lead to many lasting consequences. Although many micronutrients are important to a child, iron, zinc and vitamin A form the magnitude of public health problems related to micronutrient deficiencies.

\section{Iron}

Iron is an important micronutrient required in all stages and ages of growth and is the single most prevalent micronutrient deficiency in the world ${ }^{1}$. Iron deficiency (ID) and iron deficiency anaemia
(IDA) are two different entities, the rate of ID being almost double that of IDA ${ }^{2}$. ID could lead to neuro-developmental and behavioural problems some of which are irreversible ${ }^{3}$. Iron is important for many biological functions such as production of haemoglobin, cognitive and motor development, growth, immune functions, especially for the development of $\mathrm{T}$ helper cells. Iron deficiency leads to increased lead absorption ${ }^{4}$. Therefore, iron deficiency could directly contribute to lead poisoning. Although it is difficult to fully establish a causal relationship between ID and poor neurodevelopment due to many confounding factors, iron is important for neuronal energy metabolism, metabolism of neurotransmitters, myelination, and memory function. There are some reports of improvement in cognitive functions with treatment of $\mathrm{IDA}^{5}$. Iron is approximately distributed as $73 \%$ in haemoglobin, $12 \%$ in storage complexes (ferritin and haemosiderin) and $15 \%$ in enzymes.

In low resource settings anaemia is the main clinical and haematological yardstick used to suspect and evaluate iron deficiency states. Table 1 gives the age specific haemoglobin cut-off levels for anaemia and the degrees of severity ${ }^{6}$.

Table 1: Haemoglobin levels to diagnose anaemia at sea level $(\mathrm{g} / \mathrm{dl})^{6}$

\begin{tabular}{|l|c|c|c|c|}
\hline \multicolumn{1}{|c|}{ Population } & No anaemia & \multicolumn{3}{c|}{ Anaemia } \\
\cline { 2 - 5 } & & Mild & Moderate & Severe \\
\hline Children 6-59 months & $\geq 11.0$ & $10.0-10.9$ & $7.0-9.9$ & $<7.0$ \\
\hline Children 5-11 years & $\geq 11.5$ & $11.0-11.4$ & $8.0-10.9$ & $<8.0$ \\
\hline Children 12-18 years & $\geq 12.0$ & $11.0-11.9$ & $8.0-10.9$ & $<8.0$ \\
\hline
\end{tabular}

Iron requirement depends on the age and physiological state of the child. Anaemia prevalence of more than $5 \%$ in a population is considered to be a public health problem and the World Health Organisation (WHO) strongly recommends the use of iron supplementation as a public health intervention when anaemia prevalence is more than $20 \%$ among pre-school and school aged children ${ }^{2,7}$. It has been shown that vitamin $\mathrm{A}$ is required to liberate iron from its stores. Those who are vitamin A deficient could

${ }^{1}$ Professor in Paediatrics, Faculty of Medicine, University of Colombo have a normal serum ferritin level but low haemoglobin. Correction of vitamin A deficiency will correct the anaemia. Therefore public health programmes designed to reduce anaemia will be more effective when combined with vitamin A supplementation ${ }^{8}$.

ID and iron overload are two ends of the same spectrum and a delicate balance between the two is important. Many biochemical markers can be used to assess the iron status and are listed in table 2 with the changes in each entity ${ }^{2}$. 
Table 2: Iron status in humans, selected measures, metabolic and clinical manifestations and risks ${ }^{2}$

\begin{tabular}{|c|c|c|c|c|c|}
\hline & \multicolumn{5}{|c|}{ 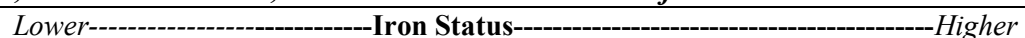 } \\
\hline & Anaemia & $\begin{array}{c}\text { Iron } \\
\text { deficiency }\end{array}$ & $\begin{array}{c}\text { Iron } \\
\text { depletion }\end{array}$ & $\begin{array}{l}\text { Normal } \\
\text { iron }\end{array}$ & $\begin{array}{c}\text { Increased iron } \\
\text { stores* }\end{array}$ \\
\hline \multirow{5}{*}{$\begin{array}{l}\text { Marrow iron stores }(\mathrm{g}) \\
\text { Plasma ferritin }(\mu \mathrm{g} / / \mathrm{l}) \\
\text { Plasma iron }(\mu \mathrm{g} / / \mathrm{l}) \\
\text { Iron protoporphyrin }(\mu \mathrm{g} / \mathrm{dl} \mathrm{RBC}) \\
\text { Transferrin saturation }(\%)\end{array}$} & 0 & 0 & 0 -trace & $2-3$ & $3-4+$ \\
\hline & $<10$ & 10 & $<20$ & $100 \pm 60$ & $>250$ \\
\hline & $<40$ & $<60$ & $<115$ & $115 \pm 50$ & $>150$ \\
\hline & 200 & 30 & 30 & 30 & 30 \\
\hline & $<10$ & $<15$ & $<30$ & $35 \pm 15$ & $>50$ \\
\hline \multirow[t]{3}{*}{ Metabolic manifestations } & Impaired cognition & $\begin{array}{l}\text { Impaired } \\
\text { cognition }\end{array}$ & & & \\
\hline & $\begin{array}{l}\text { Compromised } \\
\text { immune function }\end{array}$ & $\begin{array}{l}\text { Compromised } \\
\text { immune } \\
\text { function }\end{array}$ & & & \\
\hline & $\begin{array}{l}\text { Reduced skeletal } \\
\text { muscle function } \\
\text { and physical } \\
\text { capacity }\end{array}$ & $\begin{array}{l}\text { Impaired } \\
\text { skeletal } \\
\text { muscle } \\
\text { function }\end{array}$ & & & \\
\hline Clinical manifestations & $\begin{array}{l}\text { Fatigue Weakness } \\
\text { Increased infection }\end{array}$ & $\begin{array}{l}\text { Increased } \\
\text { infections }\end{array}$ & None & None & $\begin{array}{l}\text { Mild to severe } \\
\text { illness }\end{array}$ \\
\hline Risks & $\begin{array}{l}\text { Pregnant women: } \\
\text { Increased mortality } \\
\text { Infant with low } \\
\text { iron stores }\end{array}$ & & & & $\begin{array}{l}\text { Intake from diet, } \\
\text { fortified food and } \\
\text { supplementation in } \\
\text { normal individuals } \\
\text { has no risk due to } \\
\text { regulated absorption }\end{array}$ \\
\hline
\end{tabular}

*Iron overload is when total body iron is in excess of $4 g$

The commonest cause of anaemia is iron deficiency and as a rule-of-thumb, anaemia is considered synonymous with iron deficiency. Although serum ferritin is the frequently used bio-marker to assess iron stores, it is an acute phase protein and levels could be elevated due to underlying infection. Thus a concomitant $\mathrm{C}$ reactive protein (CRP) assay is recommended to rule out false elevations which would lead to erroneous interpretation of iron stores ${ }^{9}$. Serum ferritin level of $10 \mu \mathrm{g} / \mathrm{L}$ is considered a cut-off value for iron deficiency in children ${ }^{10}$. However, in resource-poor settings presumed ID could be "diagnosed" by way of assessing the haemoglobin response to a therapeutic trial of iron. An increase in haemoglobin concentration of $1 \mathrm{~g} / \mathrm{dl}$ after 1 month of treatment has been used to signify the presence of IDA. This approach requires iron supplementation to be adequate $(6 \mathrm{mg} / \mathrm{kg} /$ day in two divided doses) with vitamin $\mathrm{C}$ to enhance absorption and folic acid to potentiate cell division, together with patient compliance.

The American Academy of Paediatrics recommended universal screening of infants at 1 year of age with an estimation of haemoglobin levels ${ }^{9}$. However, in the local setting with high rates of exclusive and partial breast feeding and low intake of iron rich and fortified food together with higher degrees of maternal anaemia, low haemoglobin levels could occur at a younger age and therefore either screening any time after six months or having medicinal iron supplementation from 4 to 18 months of age could be recommended.
Iron supplementation

Eighty percent of the iron stores of a newborn are acquired during the last trimester and therefore iron stores would be inversely proportionate to the degree of prematurity. Furthermore, pregnancy induced hypertension related intra-uterine growth retardation (IUGR), gestational diabetes and maternal anaemia predispose the newborn to have poor iron stores, even in spite of the degree of maturity. Usually daily iron requirement of a term newborn is about $0.27 \mathrm{~g} /$ day and breast milk usually provides this with $0.35 \mathrm{~g} / \mathrm{L}$ of breast milk iron at an average consumption of $780 \mathrm{ml}^{11}$. However, after 4 months of age, iron stores in a normal birth weight term infant begin to decline. A review by Kramer \& Kakuma revealed no benefit in introducing complementary foods before 6 months with the exception of improved iron status and led to the current recommendation of extension of exclusive breastfeeding up to 6 months of age $\mathrm{e}^{12}$. They further stated that the gap in iron supply could be achieved with medicinal iron. The daily requirement of iron is about $11 \mathrm{~g} /$ day in the latter half of the first year and $7 \mathrm{~g} /$ day in the preschool child ${ }^{11}$. Increase in demand and poor diet diversity leads to the need for iron rich complementary feeds or supplementation.

The preterm infant who is fed on human milk should receive elemental iron supplementations at $2 \mathrm{mg} / \mathrm{kg}$ per day starting from 1 month of age and continued up to 12 months of age ${ }^{13}$. Exclusive breast feeding for 6 months has been shown to lead to the development of IDA at 9 months ${ }^{14}$. Friel and 
co-workers showed that iron supplementation from 1-6 months in exclusively breast fed children, induced higher haemoglobin levels at 6 months compared to non-supplemented children ${ }^{15}$. Therefore, it is recommended to supplement exclusively breast fed infants from 4 months with $1 \mathrm{mg} / \mathrm{kg} /$ day of elemental iron ${ }^{9}$. It has been shown in a systematic review that iron supplementation has no adverse effect on infection apart from a slight increase in the incidence of diarrhoea ${ }^{16}$. Children need to be encouraged to have a diverse diet rich in iron. Parents should be educated about mechanisms of enhancing iron absorption by adding citrus fruit when preparing food and reducing phytate (inositol hexaphosphate) content of diet. Parents should be encouraged to choose iron fortified food in the markets. Diets high in vegetables with phytate and low in haem iron could be optimized through diet diversification and supplementation. However, there could be barriers to iron supplementations such as poor compliance due to ignorance of carers, side effects such as nausea, vomiting, constipation, and teeth staining. It is important to brush and clean the teeth after oral supplementation. Other barriers include cost of the preparations, unavailability of adequately fortified food and risk of iron overload especially in patients with the thalassaemia trait. Thalassaemia minor resembles mild anaemia and needs treatment only if iron deficiency is present. Usually iron stores in thalassaemia minor are normal, and they are not more at risk of iron overload from iron fortified products or public health supplementation programmes than anyone else in the general population ${ }^{2}$. Universal anthelminthic treatment, irrespective of infection status, is recommended at least annually in areas where hookworm prevalence is more than $20 \%$, alongside with iron supplementation ${ }^{17}$.

The provision of daily iron supplements is a widely used strategy for improving iron status in children and is superior to weekly supplementation ${ }^{18}$. However, effectiveness of daily supplementation has been limited by poor compliance due to side effects, especially in older age groups. Therefore, intermittent use of oral iron supplements (i.e. once, twice or thrice a week on non-consecutive days) has been proposed as an effective alternative to prevent anaemia among children ${ }^{19}$. The notion behind this intervention is that intestinal cells turn over every 5-6 days and have limited iron absorptive capacity. Thus, intermittent provision of iron would expose only the new epithelial cells to this nutrient, which should improve the efficiency of absorption ${ }^{20}$. This may also minimize blockage of absorption of other minerals especially divalent cations $^{21}$. This reduced frequency of exposure to iron could also minimize the risk of infections, if it exists at $\mathrm{all}^{22}$. Therefore, intermittent iron supplementation regimens reduce associated sideeffects and increase compliance ${ }^{23}$. Intermittent iron supplementation reduces the risk of ID and IDA in children compared to placebo or no intervention, but it is less effective than daily supplementation. Intermittent supplementation is therefore a viable public health supplementation option ${ }^{5}$. It is recommended to provide $25 \mathrm{mg}$ of elemental iron to children 24-59 months and $75 \mathrm{mg}$ for 5-12 year old children weekly for 12 weeks and recommence another 12 week cycle after a 3 month gap (total of 24 months). This regimen could improve the compliance as well as biological function of iron metabolism and especially that of other divalent cations $^{7}$. No definite iron compound has been shown to be superior in its function ${ }^{5}$.

\section{Vitamin A}

Vitamin A is required for normal functioning of the visual pathway, maintenance of cell growth and epithelial integrity, red blood cell production, immune function and reproduction ${ }^{24}$. Vitamin A requirements increase during infancy and childhood due to increased growth and the need to combat infections. Inadequacies could lead to development of metaplasia in tissues especially in mucous membranes, disturbances in vision, increased vulnerability to infections and even high mortality from infections especially measles and diarrhoea $^{24}$. Vitamin A is an essential nutrient which cannot be synthesised by humans and needs to be obtained through $\operatorname{diet}^{25}$. Chronic vitamin A deficiency may develop when animal source foods and fortified foods are limited, as in diets that rely heavily on vegetables and fruits ${ }^{26}$. In lower income countries, dietary deficiency can begin very early in life especially when breastfeeding is inadequate $^{27}$. Vitamin $\mathrm{A}$ is found in two main forms, pro-vitamin A (carotenoids) and preformed vitamin A (retinol). Many forms of pro-vitamin A carotenoids are found in plants. However, only beta-carotene could be metabolised by mammals to vitamin A. Although fruits and vegetables are nutritious, normal dietary intake of plants may not provide adequate amounts of vitamin $\mathrm{A}$ as the intestinal conversion of carotenoid-to-retinol is $12: 1^{28}$. Preformed vitamin A, retinol, retinal, retinoic acid, and retinyl esters, which are the active forms, are found in foods of animal origin.

Vitamin A supplementation in pre-school age children in developing countries has been shown to reduce the risk of diarrhoea morbidity and all-cause mortality ${ }^{29}$. Although the mechanism of actions is not clear, vitamin A supplementation improves gut integrity and therefore decreases the severity of some diarrhoeal episodes ${ }^{30}$. The role of vitamin A in innate and adaptive immunity may also help to reduce susceptibility and severity of infections ${ }^{31}$. 
Provision of high doses of vitamin A at 6 monthly intervals until the age of 5 years was based on the principle that a single, large dose of vitamin $\mathrm{A}$ is well absorbed and stored in the liver, and then mobilized, as needed, over an extended period of time $^{32}$. Periodic high dose vitamin A supplementation is intended to protect against vitamin A deficiency and it helps to build the reserves. Supplementation in a vitamin A deficient population can reduce child mortality by $23 \%$ and child blindness by $70 \%$. Thus, provision of highstrength vitamin A supplements is recognized as a cost-effective way to improve child survival ${ }^{33}$. Even in the United Kingdom, daily low dose supplementation is recommended for 1-5 year old children if adequate intake from dietary sources cannot be assured ${ }^{34}$.

Vitamin A deficiency is considered a public health problem needing national supplementation programmes when the prevalence of either night blindness is $\geq 1 \%$ among $24-59$ month old children or the prevalence of vitamin A deficiency (assessed by serum retinol $\leq 0.70 \mu \mathrm{mol} / 1$ ) is $\geq 20 \%$ among 6 59 month old children ${ }^{35}$. Supplementation programmes usually use preformed vitamin $\mathrm{A}^{36}$. Oral vitamin A supplementation and food fortification are the two common methods of providing vitamin A to people whose diets are deficient.

A Cochrane review in 2010 highlighted that vitamin A supplementation saw a $24 \%$ reduction in the risk of all-cause mortality compared to controls $[\mathrm{RR}=0.76(95 \% \mathrm{CI} 0.69-0.83)]$ and a $28 \%$ reduction in diarrhoea mortality $[\mathrm{RR}=0.72(95 \%$ CI 0.57 $0.91)]^{29}$. However, there was no significant effect on cause specific mortality of measles, respiratory disease and meningitis. Vitamin A supplementation reduced the incidence of diarrhoea $[\mathrm{RR}=0.85(95 \%$ CI $0.82-0.87)]$ and measles morbidity $[R R=0.50$ (95\% CI 0.37-0.67)] but there was no significant effect on hospitalization due to diarrhoeal diseases or pneumonia ${ }^{29}$. Vitamin A mega dose $(100,000$ $200,000 \mathrm{IU})$ in supplementation programmes is well tolerated. Side-effects such as headache, nausea or vomiting, raised intracranial pressure, skin exfoliation and diarrhoea have been reported in $3-7 \%$ of these children. They are transient ${ }^{29}$. Minority sometimes develop a second phase of symptoms over the next few days such as drowsiness, malaise, lack of appetite, lethargy, itchy skin and exfoliation of $\operatorname{skin}^{37}$. There are no known deaths attributed solely to vitamin A toxicity due to overconsumption ${ }^{38}$. Usually these acute symptoms occur in children within 12-24 hours after ingesting a vitamin A dose in excess of $100 \mathrm{mg}(0.35 \mathrm{mmol} \text { or } 333300 \mathrm{IU})^{37}$. Chronic toxicity in children is caused by daily intakes of $>25,000$ IU for $>6$ years and $>100,000$ IU for $>6$ months but it may depend on the individuals to a great extent. Vitamin A, with daily intakes of 1500 $\mathrm{IU} / \mathrm{kg}$ body weight is reported to lead to toxicity over months ${ }^{39}$. They are headache, bone, joint and muscle tenderness, ataxia, visual impairment, skin disorders, alopecia, dry itchy skin, cracking of lips, hepatic toxicity, hyperlipidaemia, hypoplastic anaemia, leucopenia and periosteal thickening of long bones. Chronic toxicity recovers after stopping vitamin A intake. Permanent changes to liver, bone, vision and chronic muscle and skeletal pain may occur ${ }^{40}$.

The 1996 report on vitamin A status of Sri Lanka showed that the deficiency rates based on serum retinol level (plasma retinol of $<20 \mu \mathrm{g} / \mathrm{dl}$ ), to be $34.8 \%$ among $6-23$ year age group and about $35 \%$ among young children ${ }^{41}$. A further study done later by the Medical Research Institute (MRI) has not shown much improvement despite giving vitamin $\mathrm{A}$ at 9,18 and 36 months $^{42}$. Therefore vitamin A deficiency status in Sri Lanka is at a higher level and considered to be a public health problem.

Vitamin A supplementation is a low-cost intervention. It is effective in reducing all-cause mortality and universal supplementation is recommended for children below 5 years in areas at which the risk of vitamin A deficiency is high ${ }^{29}$. Most of the vitamin A used during supplementation campaigns is supplied in gelatin capsules where each costs approximately US\$ $0.02^{33}$. Although maternal vitamin A supplementation takes place in the immediate postnatal period, there is no convincing evidence that it helps to prevent morbidity in infants. Similarly, supplementation during early infancy (under 6 months of age) has not helped to reduce morbidity and mortality ${ }^{43}$.

Importance of vitamin A in 6 months to 5 year old children is well established and does not need further placebo control studies ${ }^{29}$. However, the dose, delivery mechanisms and frequency of supplementation needs further evaluation ${ }^{29}$.

\section{Zinc}

Zinc is involved in many enzymes as a co-factor as well as a stabilizer of the molecular structure of sub-cellular constituents and membranes ${ }^{44}$. Zinc is also involved in metabolism of carbohydrates, lipids, proteins and nucleic acid which in turn is important in genetic expression as involved in polynucleotide transcription and translation ${ }^{44}$. Zinc deficiency leads to growth retardation, delay in sexual and skeletal maturation, hair loss, dermatitis especially in acral parts and orifices, decreased appetite and susceptibility to infection due to effects on the immune system ${ }^{44}$. 
Zinc is present in all tissues and fluids of the body with a total body zinc of about $2 \mathrm{~g}$. About $60 \%$ is in skeletal muscles and $30 \%$ in bone. There are no zinc "stores" and body zinc has a rapid turnover. It gets released from bone resorption and tissue catabolism and then gets re-utilized ${ }^{44}$. Zinc is lost from the body via skin, intestine and kidneys ${ }^{45}$. Zinc absorption is concentration dependent and occurs throughout the small intestine ${ }^{46}$. Phytate and high calcium diet have a negative impact on zinc absorption while animal protein improves it ${ }^{44}$. Phytate to zinc ratio of $<5$ is best for optimum zinc absorption. Whole grain, rice, pulses and legumes contain zinc. However, zinc from animal sources is more readily absorbed. Zinc rich animal sources are oysters, red meat, lamb's liver and cheese. Bioavailability of breast milk zinc is about $80 \%{ }^{44,47}$. Zinc supplementation during an episode of diarrhoeal illness decreases length and severity of diarrhoea, enhances immune function, reduces occurrence of new diarrhoeal episodes for 2-3 months, improves appetite and enhance growth. In 2004, WHO and UNICEF jointly issued a statement recommending use of $20 \mathrm{mg}$ elemental zinc daily for 10-14 days in children older than 6 months and $10 \mathrm{mg}$ for $10-14$ days in those under 6 months of age, with diarrhoea ${ }^{48}$. This joint recommendation came after scientific consensus and recognition that zinc and low osmolarity ORS were critical for the reduction of diarrhoea mortality $^{49}$. It is estimated that more than three quarters of all diarrhoea deaths could be prevented with full coverage and utilization of zinc and Low Osmolarity $\mathrm{ORS}^{50}$. Support for these recommendations has come from the 2008 Copenhagen Consensus, a group of leading global economists that ranked zinc supplementation as the most cost-effective intervention for advancing human development ${ }^{51}$. WHO added zinc to its Essential Medicine List $^{51}$. A Cochrane review looked at the evidence on zinc supplementation in treating diarrhoeal illness ${ }^{49}$. In 22 trials, involving 8,924 children, it was shown that zinc shortened the duration of diarrhoea (MD -9.60 hours, $95 \%$ CI -18.25 to -0.96 hours). There was no beneficial effect in children below six months of age. Zinc also reduced the duration of persistent diarrhoea (MD -15.84 hours, 95\% CI -25.43 to -6.24 hours). No significant adverse events were noted apart from vomiting (RR $1.59,95 \% 1.27$ to 1.99$)^{49}$.

Zinc could be acting in different ways in exerting its beneficial actions in diarrhoeal illness. At the level of the gastrointestinal tract, zinc restores mucosal barrier integrity and enterocyte brushborder enzyme activity ${ }^{52}$, promotes the production of antibodies and circulating lymphocytes against intestinal pathogens ${ }^{53}$ and has a direct effect on ion channels, acting as a $\mathrm{K}$ channel blocker of adenosine 3-5-cyclic monophosphate mediated chlorine secretion ${ }^{54}$. It is also an important antioxidant and preserves cellular membrane integrity $^{55,56}$. Nearly $50 \%$ of zinc excretion takes place through the gastrointestinal tract and is increased during episodes of diarrhoea. Young children regularly exposed to gastrointestinal pathogens and having diets low in animal products and high in phytate-rich foods are most at risk ${ }^{49}$. Although zinc supplementation in pneumonia does not reduce symptom severity, it may reduce the case fatality rate ${ }^{57}$.

\section{Multiple micronutrient supplementation as a preventive strategy}

Vitamin and mineral deficiencies affect over 2 billion people worldwide. Iron and vitamin A deficiency contribute to the majority, although zinc could be a significant contributor alongside other vitamins and minerals ${ }^{58}$. The combined deficiencies during critical periods from pre-conception to 23 months of age would be associated with increased neonatal mortality and morbidity, as well as irreversible adverse physical and cognitive outcomes leading to unfavourable effects on health, productivity and economic growth in the long term $^{59}$. Underweight, suboptimal breast feeding, together with vitamin and mineral deficiencies are responsible for 3.9 million deaths $(35 \%$ of total deaths) and loss of 144 million disability-adjusted life years (DALYs) in children less than 5 years of age. This is about a third of all DALYs ${ }^{60}$.

Majority affected by micronutrient deficiencies are children, mainly due to their rapid growth and poor dietary practices. To improve the micronutrient status, it is important to adopt interventions to prevent micronutrient deficiencies. These include exclusive breastfeeding during the first six months of life, inclusion of micronutrient rich foods with low anti absorbents such as phytates, fortification of complementary and staple foods, control of parasitic infections and provision of nutritional supplements ${ }^{61}$.

Home or point of use fortification using multiple micronutrients in sprinkler or powder to be mixed with food is a cost effective and more readily acceptable technique of nutrition supplementation. A Cochrane review has looked at studies conducted in low income countries in Asia, Africa and the Caribbean, where different combinations of micronutrients, varying between 5 and 15 nutrients have been used ${ }^{62}$. Home fortification with multiple micronutrients reduced anaemia by $31 \%$ (RR 0.69 ; $95 \%$ CI 0.60 to 0.78 ) and iron deficiency by $51 \%$ (RR 0.49 ; 95\% CI 0.35 to 0.67 ) in infants and young children compared to no intervention or placebo. However, no effect was noted on growth. No deaths were reported in the trials and the side effects and morbidity were low ${ }^{62}$. Home 
fortification of foods with multiple micronutrient powders is an effective intervention to reduce anaemia and iron deficiency in children 6 to 23 months of age. However, the benefits of this intervention as a child survival strategy or its effects on developmental outcomes are not clear.

WHO in its 2011 position paper strongly recommended the use of home fortification of foods with multiple micronutrient powders in order to improve iron status and reduce anaemia among infants and children ${ }^{63}$. It has been recommended for use on a public health scale where anaemia prevalence is more than $20 \%$. This could be started at the same time as weaning and given as a once daily sachet for a minimum period of 2 months, followed by a 3-4 months period off supplementation before re-commencing. Therefore micronutrient powder could be used in 6 month cycles. The minimum recommended composition is $12.5 \mathrm{mg}$ of elemental iron (equals $37.5 \mathrm{mg}$ of ferrous fumarate, $62.5 \mathrm{mg}$ of ferrous sulfate heptahydrate or $105 \mathrm{mg}$ of ferrous gluconate), $300 \mu \mathrm{g}$ of retinol and $5 \mathrm{mg}$ of elemental zinc (preferably zinc gluconate) ${ }^{63}$. Many combinations of micronutrients can be used in multiple micronutrient (MMN) powders, but at present there are preparations which contain 15 micronutrients (Table 3 ) that is mainly procured and distributed by UN organizations ${ }^{64}$.

Table 3: Recommended nutrient intake (RNI) of each micronutrient per dose for children 6-59 months old ${ }^{64}$

\begin{tabular}{|l|c|}
\hline \multicolumn{1}{|c|}{ Micronutrient } & RNI \\
\hline Vitamin A ( $\mu \mathrm{g}$ RE) & 400.0 \\
\hline Vitamin D $(\mu \mathrm{g})$ & 5.0 \\
\hline Vitamin E (mg) & 5.0 \\
\hline Vitamin C (mg) & 30.0 \\
\hline Thiamine (Vitamin B1) (mg) & 0.5 \\
\hline Riboflavin (Vitamin B2) (mg) & 0.5 \\
\hline Niacin $($ Vitamin B3) (mg) & 6.0 \\
\hline Vitamin B6 (Pyridoxine) (mg) & 0.5 \\
\hline Vitamin B12 (Cobalomine) ( $\mu \mathrm{g})$ & 0.9 \\
\hline Folate $(\mu \mathrm{g})$ & 15.0 \\
\hline Iron $(\mathrm{mg})$ & 10.0 \\
\hline Zinc $(\mathrm{mg})$ & 4.1 \\
\hline Copper $(\mathrm{mg})$ & 0.56 \\
\hline Selenium $(\mu \mathrm{g})$ & 17.0 \\
\hline Iodine $(\mu \mathrm{g})$ & 90.0 \\
\hline
\end{tabular}

Micronutrient deficiencies are common among children and they could remain hidden for prolonged periods of time before developing clinical symptoms and signs. Such "dormant" states of micronutrient deficiencies could cause irreversible damage to the growing child and it is important that we anticipate such deficiencies early and take timely steps to intervene.

\section{References}

1. United Nations Administrative Committee on Coordination/Sub-Committee on Nutrition in collaboration with International Food Policy Research Institute. 4th Report on the World Nutrition Situation, January 2000: Geneva, Switzerland.

2. UNICEF/UNU/WHO/MI Technical Workshop October 1998. Preventing iron deficiency in women and children. UNICEF, New York.

3. Lozoff B, Jimenez E, Smith JB. Double burden of iron deficiency in infancy and low socioeconomic status: a longitudinal analysis of cognitive test scores to age 19 years. Archives of Pediatrics \& Adolescent Medicine 2006; 160(11):1108-13. http://dx.doi.org/10.1001/archpedi.160.11.1108

4. Watson WS, Morrison J, Bethel MI, et al. Food iron and lead absorption in humans. American Journal of Clinical Nutrition 1986; 44(2):248 -56.

5. De-Regil LM, Jefferds MED, Sylvetsky AC, Dowswell T. Intermittent iron supplementation for improving nutrition and development in children under 12 years of age. Cochrane Database of Systematic Reviews 2011; Issue 12: $\quad$ Article No.: CD009085. http://dx.doi.org/10.1002/14651858.CD009085 .pub2

6. World Health Organization, Geneva, 2011. Haemoglobin concentrations for the diagnosis of anaemia and assessment of severity WHO/NMH/NHD/MNM /11.1.

7. World Health Organization, Geneva, 2011. Guideline: Intermittent iron supplementation in preschool and school-age children.

8. BLOEM MW. Interdependence of vitamin A and iron: an important association for programmes of anaemia control. Proceedings of the Nutrition Society 1995; 54:501-8. http://dx.doi.org/10.1079/PNS19950018 
9. Baker RD, Greer FR and the Committee on Nutrition. Diagnosis and prevention of iron deficiency and iron deficiency anaemia in infants and young children ( 0 - 3 years of age). Pediatrics 2010; 126(5):1040-50.

10. Dallman PR, Siimes MA, Stekel A. Iron deficiency in infancy and childhood. American Journal of Clinical Nutrition 1980; 33(1):86 118.

11. Food and Nutrition Board. Dietary reference intakes for vitamin $\mathrm{A}$, vitamin $\mathrm{K}$, arsenic, boron, chromium, copper, iodine, iron, manganese, molybdenum, nickel, silicon, vanadium and zinc. Washington, DC: National Academies Press; 2001.

12. Kramer MS, Kakuma R. Optimal duration of exclusive breastfeeding. Cochrane Database of Systematic Reviews 2002, Issue 1. Art. No.: CD003517.

http://dx.doi.org/10.1002/14651858.CD003517

13. Nutritional needs of the premature infant. In: Kleinman RE, ed. Pediatric Nutrition Handbook. 6th ed. Elk Grove Village, IL: American Academy of Pediatrics 2008:79 112.

14. Meinzen-Derr JK, Guerrero ML, Altaye M, Ortega-Gallegos H, Ruiz-Palacios GM, Morrow AL. Risk of infant anaemia is associated with exclusive breast-feeding and maternal anemia in a Mexican cohort. Journal of Nutrition 2006; 136(2):452-8.

15. Friel JK, Aziz K, Andrews WL, Harding SV, Courage ML, Adams RJ. A double-masked, randomized control trial of iron supplementation in early infancy in healthy term breast-fed infants. Journal of Pediatrics 2003; 143(5): 582-6.

http://dx.doi.org/10.1067/S00223476(03)0030 $\underline{1-9}$

16. Gera T, Sachdev HP. Effect of iron supplementation on incidence of infectious illness in children: systematic review. British Medical Journal 2002; 325(7373): 1142. http://dx.doi.org/10.1136/bmj.325.7373.1142

17. Hall A, Hewitt G, Tuffrey V, de Silva N. A review and meta-analysis of the impact of intestinal worms on child growth and nutrition. Maternal \& Child Nutrition 2008; 4(Suppl. 1):118-236 http://dx.doi.org/10.1111/j.17408709.2007.001 $\underline{27 . x}$
18. Desai MR, Dhar R, Rosen DH, Kariuki SK, Shi YP, Kager PA, ter Kuile FO. Daily iron supplementation is more efficacious than twice weekly iron supplementation for the treatment of childhood anaemia in Western Kenya. Journal of Nutrition 2004; 134:1167-74.

19. Berger J, Aguayo VM, Téllez W, Luján C, Traissac P, San Miguel JL Weekly iron supplementation is as effective as 5 day per week iron supplementation in Bolivian school children living at high altitude. European Journal of Clinical Nutrition 1997; 6:381-6. http://dx.doi.org/10.1038/sj.ejen.1600418

20. Viteri FE, Liu X, Tolomei K, Martín A. True absorption and retention of supplemental iron is more efficient when iron is administered every three days rather than daily to ironnormal and iron-deficient rats. Journal of Nutrition 1995; 125:82-91.

21. Baqui AH, Walker CL, Zaman K, El Arifeen S, Chowdhury HR, Wahed MA, et al. Weekly iron supplementation does not block increases in serum zinc due to weekly zinc supplementation in Bangladeshi infants. Journal of Nutrition 2005; 135:2187-91.

22. Iron and Malaria Technical Working Group. Chapter 2: Mechanisms. In: Raiten D, Namaste $\mathrm{S}$, Brabin B, eds. Considerations for the safe and effective use of iron interventions. Bethesda, MD, Eunice Kennedy Shriver National Institute of Child Health and Human Development (NICHD), 2011:16-51.

23. World Health Organization Regional Office for the Western Pacific. Weekly iron and folic acid supplementation programmes for women of reproductive age: an analysis of best programme practices. Manila, 2011.

24. Sommer A, West KP Jr. Vitamin A deficiency: health, survival, and vision. New York, Oxford University Press, 1996.

25. Bates CJ. Vitamin A. Lancet 1995; 345 (8941): 31-5. http://dx.doi.org/10.1016/S01406736(95)9115 $\underline{7-X}$

26. Ramakrishnan U, Darnton-Hill I. Assessment and control of vitamin A deficiency disorders. Journal of Nutrition 2002; 132(9 Suppl):294753. 
27. Haskell MJ, Brown KH. Maternal vitamin A nutriture and the vitamin A content of human milk. Journal of Mammary Gland Biology and Neoplasia 1999; 4(3):243-57. http://dx.doi.org/10.1023/A:1018745812512

28. US Institute of Medicine, Food, Nutrition Board. Standing Committee on the Scientific Evaluation of Dietary Reference Intakes. Dietary reference intakes for vitamin A, vitamin $\mathrm{K}$, arsenic, boron, chromium, copper, iodine, iron, manganese, molybdenum, nickel, silicon, vanadium, and zinc. Washington DC: National Academy Press, 2000.

29. Imdad A, Herzer K, Mayo-Wilson E, Yakoob MY, Bhutta ZA. Vitamin A supplementation for preventing morbidity and mortality in children from 6 months to 5 years of age. Cochrane Database of Systematic Reviews 2010; Issue 12: Art. No.: CD008524. http://dx.doi.org/10.1002/14651858.CD008524 .pub2

30. Villamor E, Fawzi WW. Effects of Vitamin A supplementation on immune responses and correlation with clinical outcomes. Clinical Microbiology Reviews 2005:3:446-64. http://dx.doi.org/10.1128/CMR.18.3.446464.2 $\underline{005}$

31. Ross AC. Vitamin A supplementation and retinoic acid treatment in the regulation of antibody responses in vivo. Vitamins \& Hormones 2007; 75:197-222. http://dx.doi.org/10.1016/S00836729(06)7500 $\underline{8-7}$

32. West KP Jr, Sommer A. Delivery of oral doses of vitamin A to prevent vitamin A deficiency and nutritional blindness. A state-of-the-art review. Nutrition Policy Discussion Paper No 2. Rome, United Nations Administrative Committee on Coordination, Subcommittee on Nutrition, 1987.

33. Micronutrient Initiative. Vitamin A: the scope of the problem. Ottawa, Micronutrient Initiative, 2011. Available from: www.micronutrient.org/English/View.asp? $\mathrm{x}=5$ 77\&id=440. [Accessed on 9th October 2012].

34. Vitamin A supplements: a guide to their use in the treatment and prevention of vitamin A deficiency and xerophthalmia. 2nd ed. Prepared by WHO/UNICEF/IVACG Task Force. WHO Geneva 1997.
35. WHO. Guideline: Vitamin A supplementation in infants and children 6-59 months of age. Geneva, World Health Organization, 2011.

36. Shenai JP. Vitamin A. In: Tsang RC, Lucas A, Uauy $\mathrm{R}$ editor(s). Nutritional needs of the preterm infant: scientific basis and practical guidelines. Baltimore: Williams and Williams, 1993:87-100.

37. West CE. Vitamin A and Carotenoids. In Essentials of human nutrition. Editors, Mann J, Truswell AS. 2nd ed. Oxford University Press. 2002; 189-207.

38. Bauernfeind JC. The safe use of vitamin A. Washington, DC, International Vitamin A Consultative Group, 1980.

39. Penniston KL, Tanumihardjo SA. The acute and chronic toxic effects of vitamin A. American Journal of Clinical Nutrition 2006; 83:191-201.

40. Wickramanayake TW. Vitamins. In Food and Nutrition. 1995; 66-110.

41. Vitamin A Deficiency status of Children in Sri Lanka 1995/1996, Medical Research Institute. 1998.

42. Jayatissa R, Gunathilaka MM. Vitamin A nutrition status in Sri Lanka 2006. Medical Research Institute, 2006.

43. Gogia S, Sachdev HS. Vitamin A supplementation for the prevention of morbidity and mortality in infants six months of age or less. Cochrane Database Syst Rev. 2011, Issue 10. Art. No.: CD007480. http://dx.doi.org/10.1002/14651858.CD007480 .pub2

44. WHO 1996. Zinc. In; Trace elements in health and nutrition. WHO Geneva. 1996:72-104.

45. Milne et al. Effects of dietary zinc on whole body surface4 loss of zinc: impact on estimation of zinc retention by balance method. American Journal of Clinical Nutrition 1983; 38:181-6.

46. Lee HH, Prasad AS, Brewer GJ, Owyang C. Zinc absorption in human small intestine. American Journal of Physiology 1989; 256: G87-G91. 
47. Samman S. Trace elements: zinc, In Essentials of Human Nutrition. Ed by Mann $J$ and Truswell S. second Ed. Oxford University press. 2002; 156-64.

48. WHO/UNICEF joint statement. Clinical management of acute diarrhoea. 2004.

49. Lazzerini M, Ronfani L. Oral zinc for treating diarrhoea in children. Cochrane Database Systematic Reviews 2008, Issue 3. Art. No.: CD005436.

http://dx.doi.org/10.1002/14651858.CD005436 .pub2

50. Jones G, Steketee RW, Black RE, Bhutta ZA, Morris SS. How many child deaths can we prevent this year? Lancet 2003; 362:65-71. http://dx.doi.org/10.1016/S01406736(03)13811-1

51. Horton S, Begin F, Greig A, Lakshman A. Best Practice Paper Micronutrient Supplements for Child Survival (Vitamin A and Zinc) Copenhagen Consensus 2008 Results. Frederiksberg: Copenhagen Consensus Center; 2008. Available from: http://www.copenhagenconsensus.com/Resear $\mathrm{ch} /$ Index/Hunger.aspx [Accessed on 23rd September 2012].

52. Shankar AH, Prasad AS. Zinc and immune function: the biological basis of altered resistance to infection. American Journal of Clinical Nutrition 1998; 68 (Suppl 2):447s63s.

53. Raqib R, Roy SK, Rahman MJ, Azim T, Ameer SS, Chisti J, et al. Effect of zinc supplementation on immune and inflammatory responses in pediatric patients with shigellosis. American Journal of Clinical Nutrition 2004; 79(3):444-50.

54. Hoque KM, Sarker R, Guggino SE, Tse CM. A New Insight into Pathophysiological Mechanisms of Zinc in Diarrhea. Annals of the New York Academy of Sciences 2009; 1165: 279-84.

$\underline{\text { http://dx.doi.org/10.1111/j.17496632.2009.044 }}$ $\underline{42 . x}$

55. O'Dell BL. Role of Zinc in Plasma Membrane Function1. Journal of Nutrition 2000; 130: $1432 \mathrm{~S}-6 \mathrm{~S}$

56. Powell SR. The Antioxidant Properties of Zinc. Journal of Nutrition 2000; 130:1447S$54 \mathrm{~S}$.
57. Srinivasan MG, Ndeezi G, Mboijana CK, Kiguli S, Bimenya GS, Nankabirwa V, et al. Zinc adjunct therapy reduces case fatality in severe childhood pneumonia: a randomized double blind placebo-controlled trial. $B M C$ Medicine 2012; 10:14. http://dx.doi.org/10.1186/1741-7015-10-14

58. Micronutrient Initiative, Flour Fortification Initiative, USAID, GAIN, WHO, World Bank, UNICEF. Investing in the Future: A united call to action on Vitamin and Mineral Deficiencies: Global Report 2009. Ottawa, Canada: 2009.

59. Sanghvi T, Ross J, Heymann H. Why is reducing vitamin and mineral deficiencies critical for development? The links between VMD and survival, health, education and productivity. Food \& Nutrition Bulletin 2007; 28 (Suppl. 1):S167-S173.

60. World Health Organization. Global health risk. Mortality and burden of disease attributable to selected major risks. Geneva, 2009. Available from: http://www.who.int/healthinfo/global_burden [Accessed on 21st June 2011]

61. De Maeyer EM. Preventing and controlling iron deficiency anaemia through primary health care. Geneva, World Health Organization, 1989. Available from: http://www.who.int/nutrition/publications/micr onutrients/anaemia_iron_deficiency/92415424 97.pdf, [Accessed 21st February 2012].

62. De-Regil LM, Suchdev PS, Vist GE, Walleser S, Peña-Rosas JP. Home fortification of foods with multiple micronutrient powders for health and nutrition in children under two years of age. Cochrane Database Systematic Reviews 2011, Issue 9. Art. No.: CD008959. http://dx.doi.org/10.1002/14651858.CD008959 .pub2

63. WHO Guideline: Use of multiple micronutrient powders for home fortification of foods consumed by infants and children 623 months of age. WHO 2011.

64. Programmatic guidance brief on use of micronutrient powders (mnp) for home fortification. Home fortification technical group. Available from: http:/hftag.gainhealth.org/sites/hftag.gainhealt h.org/files/HF- [Accessed on 20th October 2012]. 